\title{
A comparison of pro- pofol and thiopentone as induction agents in outpatient surgery
}

We studied 90 healthy ASA physical slatus I or II female patients scheduled for outpatient therapeutic abortions. Sixty patients received induction doses of propofol $\left(2.5 \mathrm{mg} \cdot \mathrm{kg}^{-i}\right)$ and 30 patients received thiopentone $\left(4 \mathrm{mg} \cdot \mathrm{kg}^{-1}\right)$. Anaesthesia was maintained with nitrous oxide plus additionat doses of the agent used for induction. Comparisons were made regarding the efficacy of induction and maintenance, rapidity of recovery, haemodynamic and respiratory variables and side effects.

The number of "excellent" inductions was significantly different ( $p=0.02$ ), with 97 per cent of the patients induced with propofol and 80 per cent of the patients induced with thiopentone receiving this rating. A larger number of patients receiving propofol exhibited minor extraneous muscular movenent during induction $(p=0.01)$. Recovery for the propofol group was significantly more rapid than with the thiopentone group $(p=0.001)$. The respiratory effect of the iwo drugs was not significantly different. Propofol caused a decrease in pulse rate and a decrease in systolic, diastolic and mear pressure which were significontly greater than with thiopentone.

From the observations made we conclude that propofol has the potential to be an excellent induction and maintenance agent for outpatient surgery in combination with nitrous oxide alone.

Key words

ANAESTHESIA: outPatient; ANAESTHETICS INTRA VENOUS: propofol, thiopentone.

From the Department of Anaesthesia, Mount Sinai Hospital, 600 University Avenue, Toronta, Ontario, M5G 1 X.5.
Diisopropylphenol (propofol) is an induction agent which has been studied in Europe but only recently has become available for clinical trials in North America. Since propofol is not water soluble, its original formulation involved solution in cremophor-EL. Induction with this formulation was unacceptable because of the high incidence of allergic phenomena to the cremophor base. Recently an aqueous emulsion of propofol has been produced which should avoid the problems attributed to cremophor. This milky emulsion has made it difficult to blind the observer to which drug is being used and to date no previous study has made an attempt to solve this problem. This study attempts to do so. As well, we have induced and maintained anaesthesia with the study drugs in unpremedicated outputients using only nitrous oxide supplementation. This allowed us to evaluate the safety and efficacy of propofol and compare it to thiopentone as an induction and maintenance agent for short outpatient procedures without further supplementation.

\section{Methods}

With approval from the Human Subjects Review Committee at the University of Toronto, informed consent was obtained from 90 healthy female patients. The patients were ASA physical status I or II, between 18 and 40 years of age and scheduled for therapeutic abortions in the first trimester of pregnancy. The patients were randomly assigned to receive either propofol or thiopentone with 60 patients receiving propofol and 30 receiving thiopentone. This numerical imbalance was deliberate and designed to increase our experience with the new drug without prolonging the study or decreasing its statistical power. We excluded those patients with a history of allergy to the trial drugs and those who had had an advcrse anaesthetic reaction of any kind. We also excluded morbidly obese patients ( 30 per cent above ideal weight) and those who could not communicate effectively with the investigator. All anaesthetics were administered by the author and all observations during anaesthesia and recovery were made and recorded by a research assistant 
who was unaware of which drug had been administered. Since propofol in aqueous emulsion is a milky substance which is easily distinguished from thiopentone, all syringes were taped to prevent the observer from seeing their contents. A small window in the tape was left so the volume of the contents of the syringe could be seen by the anaesthetist and the appropriate dose administered. The patients had no knowledge of which drug they had received until the termination of the study.

The non-premedicated patients were placed on the operating room table and were monitored with a noninvasive blood pressure ocillometric apparatus (Datascope),* lead $\amalg$ of the electrocardiogram, precordial stethoscope and infrared $\mathrm{CO}_{2}$ analyzer (Beckman). An intravenous infusion was begun in an antecubital fossa or forearm with five per cent dextrose in lactated Ringer's solution. Baseline measurements were then recorded of systolic, diastolic and mean blood pressure, pulse rate, end-tidal $\mathrm{PCO}_{2}$ and respiratory rate. The trial drug (either $4 \mathrm{mg} \cdot \mathrm{kg}^{-1}$ of thiopentone or $2.5 \mathrm{mg} \cdot \mathrm{kg}^{-1}$ of propofol) was injected into the intravenous tubing over a period of 20-30 seconds. The patient was instructed to count backwards from one hundred and was advised to note any feeling at the IV site. Induction time was determined as the time measured by a stop watch until the counting ceased and the patient failed to respond to command. If the patient failed to fall asleep within one minute a second dose ( 50 per cent of the first) was administered. If the patient failed to fall asleep within one minute of the second dose a third dose (50 per cent of the first dose) was administered. If the third dose failed to produce sleep the induction was considered a failure. From this point induction variables of systolic, diastolic and mean blood pressure, pulse rate, respiratory rate and end-tidal $\mathrm{PCO}_{2}$ were measured each minute for three minutes while the patient breathed 100 per cent $\mathrm{O}_{2}$. At the end of three minutes the induction was considered to be complete and $\mathrm{N}_{2} \mathrm{O} 70$ per cent, and $\mathrm{O}_{2} 30$ per cent were administered. Anaesthesia was maintained with intermittent boluses of 50 per cent of the induction dose of the test drug in response to clinical signs of light anaesthesia which included movement in response to surgical stimuti, tearing, phonation, increases in blood pressure, pulse rate and respiratory rate or depth. The physiological variables were recorded each minute during the maintenance period. When the procedure was terminated $\mathrm{N}_{2} \mathrm{O}$ was stopped, 100 per cent $\mathrm{O}_{2}$ was delivered for one minute and recovery was considered to have commenced.

All periods of apnoea greater than 30 seconds as well as all excitatory movements were recorded. In the post-

${ }^{*}$ Datascope Corporation, Paramus, NI, U.S.A operative period, beginning with the termination of $\mathrm{N}_{2} \mathrm{O}$, the time to opening of the eyes, response to verbal command and orientation were noted. Post Anaesthesia Recovery Scores (PARR) ${ }^{\prime}$ were measured every five minutes for the first 20 minutes and then every ten minutes up to 60 minutes. The PARR score was determined by considering the following factors: motor re sponse, respiration, blood pressure, consciousness and skin colour. Each factor was scored 0,1 or 2 with 0 being the "worst" and 2 being the "best" recovery.

The evaluation of induction and maintenance was rated as either excellent, good or poor. The induction was considered excellent if the patient fell asleep in the firs minute and stayed asleep; good if the patient fell asleep in the first minute but required a second dose before the three-minute period had elapsed and poor if the patient did not fall asleep within one minute or awakened within three minutes and did not fall asleep with the second dose. Maintenance was considered excellent if respiratory and haemodynamic parameters remained within ten per cent of preoperative values; good if mild respiratory or haemodynamic depression occurred, defined as end-tidal $\mathrm{PCO}_{2}$ between $45-55 \mathrm{mmHg}$ and blood pressure and pulse remaining within 30 per cent of preoperative values with no ECG dysrhythmias and poor if there was evidence of moderate to severe respiratory or haemodynamic depression, defined as end-tidal $\mathrm{PCO}_{2}$ above $55 \mathrm{mmHg}$ and/or blood pressure and pulse rate changes greater than 30 per cent of preoperative values and/or ECG dysrhythmias observed.

Statistical significance $(p<0.05$ ) was based on a two-tailed hypothesis. Overall response to induction and maintenance were compared between anaesthetic agents using a Fisher's exact test. Haemodynamic and respiratory parameters were compared between drugs using a repeated measures analysis of variance. In the presence of a significant drug-time interaction, change from baseline to each of the other protocol time points were examined using Wilcoxon rank-sum tests. Time to awakening, response time to a verbal command and time to orientation were mcasured from the time at which all anaesthetic agents were discontinued. All recovery times were compared between drugs using an analysis of variance model with duration of anaesthesia as a covariate. Each of the five dimensions of the PARR score were compared between treatment groups using multivariate categorical data modelling techniques as supplied in the CATMOD procedure of SAS. Comparisons between agents were adjusted for the time from start of the postanaesthetic recovery. Proportions of patients with adverse reactions and excitatory effects were analyzed using a Fisher's exact test. 
TABLE I Summary of induction and maintenance results (Mean \pm SD)

\begin{tabular}{|c|c|c|c|}
\hline & & \multicolumn{2}{|c|}{ Study medication } \\
\hline & & $\begin{array}{l}\text { Propofol } \\
(n=60)\end{array}$ & $\begin{array}{l}\text { Thiopentorle } \\
(n=30)\end{array}$ \\
\hline \multirow[t]{2}{*}{ Induction of anaesthesia } & No. of patients induced with dose 1 & 59 & 28 \\
\hline & No. of patients induced with dose 2 & 1 & 2 \\
\hline \multicolumn{4}{|l|}{ Elapsed time to onset of induction } \\
\hline (seconds) & & $31.9=9.9$ & $32.4 \pm 13.4$ \\
\hline Induction dose $\left(\mathrm{mg} \cdot \mathrm{kg}^{-1}\right)$ & & $2.49 \pm 0.07$ & $3.98 \pm 0.13$ \\
\hline \multicolumn{4}{|l|}{ Maintenance dose } \\
\hline$\left(\mathrm{mg} \cdot \mathrm{kg}^{-1} \cdot \min ^{-1}\right)$ & & $0.55 \pm 0.13$ & $1.07 \pm 0.21$ \\
\hline \multirow[t]{2}{*}{ Number of maintenance boluses* } & $<2$ & 48 & 8 \\
\hline & $>2$ & 12 & 22 \\
\hline
\end{tabular}

*Distribution of maintenance boluses significan:ly different between treatment groups $(p<0.0001)$.

TABLE IJ Overall efficacy evaluation

\begin{tabular}{|c|c|c|c|c|}
\hline & \multicolumn{4}{|c|}{ Siudy medication } \\
\hline & \multicolumn{2}{|c|}{$\begin{array}{l}\text { Propofol } \\
n=60\end{array}$} & \multicolumn{2}{|c|}{$\begin{array}{l}\text { Thiopenrone } \\
n=30\end{array}$} \\
\hline & $n=60$ & $\%$ & $n=30$ & $\%$ \\
\hline \multicolumn{5}{|l|}{ Induction* } \\
\hline Excellent & 58 & 96.7 & 24 & 80 \\
\hline Good & 1 & 1.6 & 4 & 13 \\
\hline Poor & I & 1,6 & 2 & 7 \\
\hline \multicolumn{5}{|l|}{ Maintenance } \\
\hline Excellent & 52 & 86.7 & 27 & 90 \\
\hline Good & 7 & 11.6 & 1 & 3 \\
\hline Poor & 1 & 1.6 & 2 & 7 \\
\hline
\end{tabular}

* Distribution of induction responses significanily different between treatment groups $(\mathrm{p}=0.02$ )

\section{Results}

Induction and maintenance of anaesthesia

All patients in both treatment groups fell asleep during the three-minute induction period. The range of dosages of the initial induction injection was $2.19-2.64 \mathrm{mg} \cdot \mathrm{kg}^{-1}$ for propofol and $3.52-4.24 \mathrm{mg} \mathrm{kg}^{-1}$ for thiopentone. As seen in Table 1 , the mean time to the onset of induction was 31.9 seconds for propofol and $32.4 \mathrm{sec}$ onds for thiopentone. The distribution of these induction times were not statistically significantly different $(\mathrm{p}=$ 0.69 ). The overall induction was considered excellent for 97 per cent $(58 / 60)$ of the propofol group and for 80 per cent (24/30) of the thiopentone group. Fifty-nine of the 60 patients receiving propofol and 28 of the 30 patients receiving thiopentone were successfully induced with the initial induction injection (Table II). The total doses administered during induction were $142 \mathrm{mg}$ for propofol and $250 \mathrm{mg}$ for thiopentore. Seven patients in the propofol group exhibited musculoskeletal movement of the extremities during induction which was mild and did not interfere with induction. No patient in the thiopentone group exhibited such movement ( $p=0.01$ ). There were no differences between treatment groups for injection site adverse experiences. Twenty-seven ( 45 per cent) patients in the propofol group and 11 ( 37 per cent) patients in the thiopentone group experienced apnoea during the induction period $(\mathrm{p}=0.5)$. Two patients in the propofol group required manual ventilation for a brief period during induction.

At the end of the three-minute induction period, anaesthesia was maintained with 70 per cent $\mathrm{N}_{2} \mathrm{O}, 30$ per cent $\mathrm{O}_{2}$ and repeat bolus injections of 50 per cent of the induction dose of each study drug. One patient in the propofol group sustained a perforated uterus during the procedure and underwent immediate laparoscopy. The therapeutic abortion had been completed according to the protocol and therefore the patient was included in the appraisal of maintenance for this period. The median time between the start of induction and first maintenance bolus was four minutes for propofol and three minutes for thiopentone $(p=0.01$ ). The median time between the start of the initial induction injection and the final bolus was four minutes for both propofol and thiopentone groups (NS, $p=0.11$ ). The median total duration of anaesthesia was seven minutes for both propofol and thiopentone (NS, $p=0.21$ ). The median doses given as maintenance boluses were $74.0 \mathrm{mg}$ for propofol and $213.7 \mathrm{mg}$ for thiopentone. Seventy-seven per cent $(46 / 60)$ of patients in the propofol group received only one bolus injection during the maintenance period while 73 per cent $(22 / 30)$ of patients in the thiopentone group required two or more bolus doses $(p<0.0001)$. The median total doses received during the study were $221 \mathrm{mg}$ for propofol and $480 \mathrm{mg}$ for thiopentone. The overall maintenance 


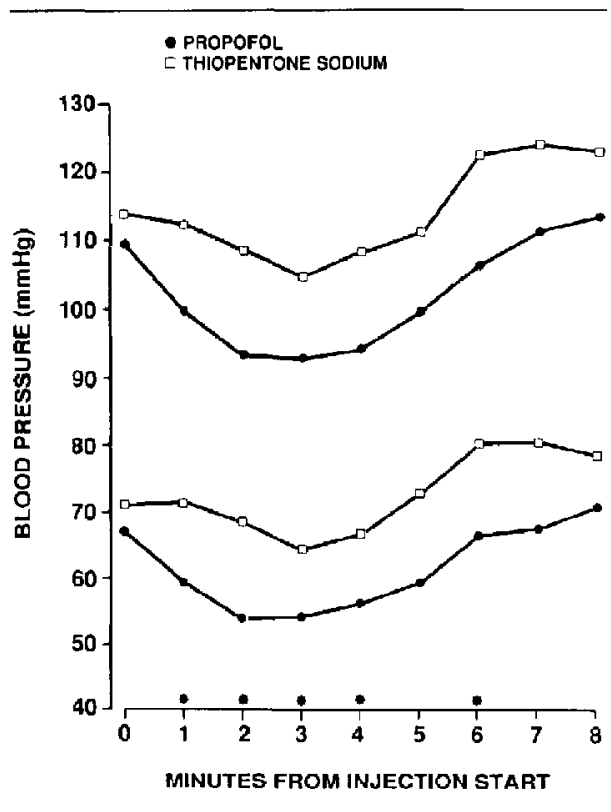

FIGURE I Mean systolic and diastolic blood pressure versus time. *The differences between agents are statistically significant for systolic and diastolic blood pressure at $1,2,3,4$, and 6 minutes (see text for p. values).

was considered excellent in 87 per cent $(52 / 60)$ of the propofol group and 90 per cent (27/30) of the thiopentone group $(p=0.75$ ). One patient receiving propofol was apnoeic for 45 seconds but did not require ventilation. None of the patients receiving thiopentone were apnoeic during maintenance.

Haemudynamic and respiratory assessment

Systolic blood pressures decreased consistently throughout the three-minute induction period for propofol, while average values for the thiopentone group showed only slight decreases during induction. Average values increased thereafter for both anaesthetic agents and remained stable throughout the observation period. Changes from baseline were statistically significantly different between drugs at $1,2,3,4$, and 6 minutes $(p=0.002, p=$ $0.0007, p=0.01, p=0.01$ and $p=0.006$ ) (Figure 1).

Average diastolic blood pressure values in the propofol group decreased during the three-minute induction period. Average values in the thiopentone group increased during the first minute and then decreased during the remainder of the induction. Diastolic blood pressures

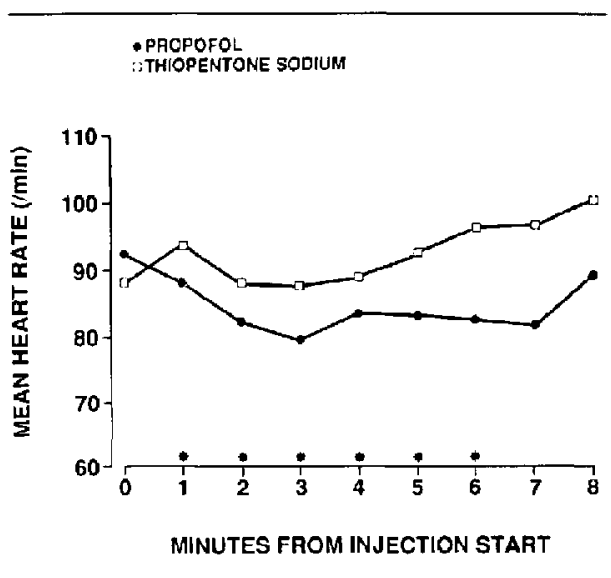

FlGURE 2 Mean heart rate versus time.

* Statistically significantly different at all analyzed time points (see text for $p$ values)

then began to increase for both agents and were relatively constant throughout the anaesthetic period. Changes from baseline were statistically significantly different at $1,2,3,4$ and 6 minutes $(p=0.001, p=0.0004, p=$ $0.01, p=0.005$ and $p=0.03$ ) (Figure 1).

Similar patterns were seen for mean blood pressure during the induction and maintenance periods. Changes from baseline were statistically significantly different between anaesthetic agents at all analyzed time points $(\mathrm{p}=$ $0.004, \mathrm{p}=0.0003, \mathrm{p}=0.004, \mathrm{p}=0.04, \mathrm{p}=0.03$ and $\mathrm{p}=0.04)$.

Heart rates decreased throughout the induction periad in the propofol group, while average values increased during the first minute and then decreased in the thiopentone group. Average heart rates then began to increase in both groups and were relatively constant throughout the remainder of anaesthesia. Changes from baseline were statistically significantly different at all analyzed time periods ( $p=0.002, p=0.01, p=0.006, p=0.009$, $p=0.0006$, and $p=0.0001$ ) (Figure 2).

Respiratory rates increased consistently throughout in duction and maintenance periods for both propofol and thiopentone groups. Propofol was associated with greater increases in respiratory rates throughout the induction and maintenance periods. After adjusting for protocol time, there was a statistically significant treatment effect $(\mathrm{p}=0.0007)$.

Average end-tidal $\mathrm{CO}_{2}$ values increased initially and then decreased and stabilized for both anaesthetic agents. Changes from baseline were significantly different be- 
tween propofol and thiopentone groups at six minutes after the induction onset with the mean $\mathrm{PCO}_{2}$ for the propofol group being 37.5 and the mean $\mathrm{PCO}_{2}$ for the thiopentone group being $34.8(\mathrm{p}=0.005)$.

\section{Recovery evaluation}

Time to awakening, response time to a verbal command, and time to orientation were measured from the termination of all anaesthesia. An adjusted comparison was performed for recovery times using the total length of anaesthesia as a covariate. After adjustment, there were statistically significant treatment differences for time to awakening and time to response to verbal command ( $\mathrm{p}=$ 0.001 and $p=0.0001$ ). These recovery times were significantly shorter for the propofol group.

The adjusted mean time to awakening was 4.6 minutes for patients receiving propofol and 6.6 minutes for those receiving thiopentone. After adjustment, the mean time to response to a verbal command was 5.8 minutes for propofol and 8.7 minutes for thiopentone.

Using all available data, there was not a statistically significant difference between treatments for time to orientation ( $p=0.38$ ). It was noted, however, that one patient who received propofol required substantially longer ( 1 hour, 41 minutes) than all other patients to become oriented. This patient suffered from unusual hysteria and agitation following surgery and was administered diazepam to quiet this reaction. When data from this patient were excluded from the analysis, there was a statistically significant treatment difference ( $p=0.0001$ ). Again, recovery times were significantly shorter for the propofol group.

The adjusted mean time to orientation with all patients included was 9.5 minutes for propofol and 11.6 minutes for thiopentone. Excluding the one patient with prolonged recovery, the adjusted mean time to orientation was 7.9 minutes for propofol and 11.6 minutes for thiopentone.

PARR questionnaires were completed for each patient one minute after arrival in the recovery room, every five minutes up to 20 minutes, and thereafter every ten minutes up to 60 minutes. A PARR questionnaire was not completed for one patient in the propofol group. In addition, results for the pain character dimension include only those patients who reported moderate or severe pain. After adjustment for time differences, there were no statistically significant differences between drugs for any of the five dimensions in the PARR score $(p>0.24$ in each case, categorical data models).

\section{Adverse reaction rates}

Adverse reactions occurred in 38 per cent of the patients receiving propofol and 47 per cent of the patients receiv-
TABLE llI Adverse reactions

\begin{tabular}{lll}
\hline & $\begin{array}{l}\text { Propofol } \\
n=60\end{array}$ & $\begin{array}{l}\text { Thiopentone } \\
n=30\end{array}$ \\
\hline $\begin{array}{ll}\text { Nausea and yomiting } \\
\quad \text { Nausea }\end{array}$ & 2 & 2 \\
Vomiting & 5 & 7 \\
Movement* & 7 & 0 \\
Cough, hiccough, sneeze & 3 & 0 \\
Flushing & 1 & 0 \\
Rash & 0 & 1 \\
Arrythmia & 0 & 0 \\
\hline
\end{tabular}

* Statistically siguificant difference between treatment groups $(p=0.01)$.

ing thiopentone. This was not statistically significant $(\mathrm{p}=$ 0.50). Patients receiving propofol had more excitatory effects (musculoskeletal movernent, hiccoughing) than did patients receiving thiopentone $(p=0,1)$. There were no significant differences in nausea and vomiting or injection site adverse experiences between groups (Table III).

\section{Discussion}

This study was performed in unpremedicated outpatients using propofol or thiopentone without supplementation other than nitrous oxide. Thus our observations were not affected by the addition of narcotics or volatile anaesthetics. The maintenance of anaesthesia proved to be easy and trouble-free with few intraoperative or postoperative problems.

Other studies have evaluated propofol ${ }^{2-5}$ but did not attempt a double blind approach because this agent could be identified by its physical appearance. Our use of tape to conceal the contents of the syringes partially solved. this problem. It allowed us to eliminate observer and patient bias but could not eliminate the potential for bias by the anaesthetist. However, this design does approach the idcal goal of a double-blind study more closely than in earlier studies.

Another experimental problem was the attempt to evaluate equipotent doses. The doses chosen $\left(2.5 \mathrm{mg} \cdot \mathrm{kg}^{-1}\right)$ propofol, $4 \mathrm{mg} \cdot \mathrm{kg}^{-\mathrm{t}}$ thiopnetone) reflect doses reported to be equipotent. ${ }^{6.7,15}$ However, we found that for these very short procedures the median dose was $221 \mathrm{mg}$ of propofol and $480 \mathrm{mg}$ of thiopentone. This suggests that propofol is 2.2 times as potent as thiopentone, assuming that clinical judgement was accurate as to when the repeat doses were given. Since the induction doses used were fixed at a ratio of 1.6 this would account for the greater number of repeat injections required for the thiopenione group and could account for the fact that the first maintenance injection, if necessary, was statistically longer 
after the induction (four minutes vs three minutes) in the propofol group. When comparing the haemodynamic effects and rccovery time for the two drugs if any error has becn made in the search for equipotency it will be on the side of propofol being given in a larger dose than required.

Some excitatory side effects were noted with propofol but not with thiopentone. These included minor extraneous movements of the arms or legs which did not interfere with the conduct of the anaesthetic or the surgical procedure. These movements have been observed by other investigators. ${ }^{6,7}$ There were also other minor side effects, such as nausea and vomiting, flushing, coughing, hiccoughing and sneezing. The incidence of pain on injection of propofol was low. This is different from the experiences of others who noted a high incidence of pain on injection. ${ }^{8-10}$ The difference may lie in the fact that most of our patients had free flowing intravenous infusions running in an antecubital fossa, in order to allow blood to be taken for other studies. None of these patients experienced pain on injection. The four patients who had pain on injection had intravenous sites in the forearm or wrist. This variation in pain incidence depending on the injection site was also noted by Briggs. ${ }^{10}$

Propofol produced a statistically greater decrease in systolic, diastolic and mean pressures and pulse rate. The decreases in blood pressure seen with propofol were accompanied by a decreased pulse rate. This should make propofol a more favourable agent in patients with ischaemic heart disease, owing to a more favourable supply/demand ratio of the myocardium. " We have no information as to whether the fall in blood pressure was due to a decreased cardiac output or peripheral resistance but experimental data indicates that the latter is more likely. ${ }^{12}$

The respiratory effects of both anaesthetics were similar. Both agents produced shor periods of apnoea in some patients which was not a clinical problem. The low normal mean control $\mathrm{PCO}_{2}$ (36.8) in this group of anxious unpremedicated women was not unexpected. Neither agent produced respiratory depression of clinical significance.

As far as recovery from anaesthesia is concemed, one of the most important areas in evaluating agents for outpatient use, propofol was associated with a shorter mean awakening time, a shorter time to response to verbal command, and, if one excluces the single patient who received propofol and had a very prolonged recovery almost certainly not due to the agent, a shorter time to full orientation. It would appear that the pharmacokinetic features of propofol, including significant metab. olism with extremely high total body clearance ${ }^{13}$ and short $T_{1} B,{ }^{14}$ make it an excellent drug for induction and maintenance of outpatient anaesthesia without further supplementation.

In conclusion, the results of this study suggest that propofol compares favourably with thiopentone as an agent for outpaticnt anaesthesia supplemented only by nitrous oxide. It produces rapid, pleasant, safe anacsthesia with few untoward side effects and only minor haemodynamic effects which include decreases in blood pressure and pulse rate. Its respiratory effects are minimal and recovery is rapid.

\section{Acknowledgement}

The author gratefully acknowledges $\mathbf{L}$. Weinper BA, for her technical assistance.

\section{References}

1 Aldrete, JA, Kroulik $D$. Post anesthesia recovery score. Anesth Analg 1970; 49: 924-34.

2 Mackenzie N, Grant IS. Comparison of the new emulsion formulation of propofol with methohexitone and thiopentone for induction of anaesthesia in day cases. Br J Anaesth 1985; 57: 725-31.

3 Wells JKG. Comparison of ICI 35868, etomidate and methohexitonc for day-case anaesthesia. Br J Anaesth 1985 ; 57: 732-5.

4 Kay $N H$, Uppington J. Sear JW, Allen MC. Use of an emulsion of ICI 35868 (propofol) for the induction and main. tenance of anaesthesia. Br J Anaesth 1985; 57: 736-42.

5 Redfern $N$, Siafford MA, Hull CJ. Incremental propofol for short procedures. Br J Anaesth 1985; 57: 1178-82.

6 Mouton SM, Bullington J, Davis L, Fisher $K$, Ramsey 3 , Wood $M$. A comparison of diprivan and thiopental for the induction of anesthesia. Anesthesiology 1985; 63: A364.

7 Plosker H, Sampson 1 , Cohen $M$, Kaplan JA. A comparison of diprivan and thiamylal sodium for the induction and maintenance of outpatient anesthesia. Anesthesiology 1985; 63: A366.

8 Cummings GC, Dixon .J. Kay NH et al. Dose requirements of ICI 35,868 (Propofol, 'Diprivan') in a new formulation for induction of anaesthesia. Anaesthesia 1984; 39 : $1168-71$.

9 Major E, Verniquet A.JW, Waddell TK, Savege TM, Hoffer $D E$, Aveling W. A study of three doses of ICI 35868 for induction and maintenance of anaesthesia. Br J Anaesth 1981: $53: 267-72$.

10 Briggs LP, Clarke RSJ, Dundee JW, Moore J, Behar M. Wright PJ. Use of di-isopropyl pheno] as main agent for short procedures. Br J Anaesth 1981; 53: 1197-1202.

11 Buffington $C W$. Hemodynamic determinants of myocardial dysfunction in the presence of coronary stenosis in dogs. Anesthesiology 1985; 63: 651-62. 
12 Patrick MR, Blair IJ, Feneck RO, Sebel PS. A comparison of the hemodynamic effects of propofol (diprivan) and thiopentone in patients with coronary artery disease. Postgraduate Medical Journal 1985; 61: (Suppl 3) 23-7.

13 Schutler J, Stoeckel H, Schwilden H. Pharmacokinetic and pharmacodynamic modelling of propofol ('diprivan') in volunteers and surgical patients. Postgraduate Med J 1985; 61: (Suppl 3) 53-4.

14 Adam HK. Briggs LP, Bahar M, Douglas EJ, Dundee JW. Pharmacokinetic cvaluation of ICI 35868 in man. Single induction doses with different rates of injection. $\mathrm{Br} \mathrm{J}$ Anaesth 1983; 55: 97.

15 Fahmay NR, Alkhouli HM, Sunder N, Smith D, Kelley MM. Diprivan. A new intravenous induction agent. $A$ comparison with thiopental. Anesthesiology 1985; 63: A363.
Résumé

On a étudié 90 patientes en bonre santé classe ASA I et II cédulées en externe pour avortement thérupeutique. Soixamte patientes ont regu des doses d'induction de $\left(2.5 \mathrm{mg} \cdot \mathrm{kg}^{-1}\right)$ de propofol et trente patientes ont reçu $\left(4 \mathrm{mg} \cdot \mathrm{kg}^{-1}\right)$ de thiopentone. L'anesthésie était maintenue avec du protoxide d'azote et des doses additionnelles de l'agent d'induction. On a comparé l'efficaciré de l'induction et du maintien, la rapidité du réveil. les données hémodynamiques et respiratoires ainsi que les efforts secondaires.

Le nombre d'inductions "excellentes" était significarivement différent $(p=0.02$ ) chez 97 pour cent des patientes induites avec le propofol et 80 pour cent chez celles induites an thiopentoste. Un plus grand nombre de patientes ayant reçu de propofol ont démontré des mouvements musculaires involontaires lors de l'induction $\{p=0.01)$. Le réveil était significativement plus rapide pour le groupe propofol que le groupe thiopentone $(p=0.001)$, Les effets respiratoires des deux médicaments n'êtaient pas différents. Le propofol a provoqué une diminution du pouls et de la tension artérielle systolique, diastolique at moyenne qui était significativement plus grande que le groupe thiopentone.

De ces observations, on conclue que le propofol présente le potentiel d'être un excellent agent pour l'induction et le maintien de l'anesthésie pour les patients externes si combinés au protoxide d'azote seul. 